\title{
The Relationship Between Social Capital and Depressive Symptoms Among the Elderly in China: The Mediating Role of Life Satisfaction
}

This article was published in the following Dove Press journal: Risk Management and Healthcare Policy

\author{
Jian Sun' \\ Tong Xiao ${ }^{2}$ \\ Shoujun Lyu $\mathbb{D}^{1,3}$ \\ Rui Zhao ${ }^{4}$
}

'School of International and Public Affairs, Shanghai Jiao Tong University, Shanghai 200030, People's Republic of China; ${ }^{2}$ School of Project Management and Real Estate, Henan University of Economics and Law, Zhengzhou, Henan 450046, People's Republic of China; ${ }^{3}$ China Institute for Urban Governance, Shanghai Jiao Tong University, Shanghai 200030, People's Republic of China; ${ }^{4}$ Affiliated Hospital of Hebei University, Baoding, Hebei 071000, People's Republic of China
Correspondence: Shoujun Lyu School of International and Public Affairs, China Institute for Urban Governance, Shanghai Jiao Tong University, 1954, Huashan Road, Xuhui District, Shanghai 200030, People's Republic of China

Tel +86 I59 21083352

Email sjlv@sjtu.edu.cn
Background and Aim: Depression has become a serious health and social issue in recent years in China. This study aims to explore the relationship between social capital and depressive symptoms among the elderly in China, with a particular focus on the mediating role of life satisfaction.

Methods: The data of this study were sourced from the 2016 wave of China Family Panel Studies (CFPS), involving 1243 older adults aged 60 and above. A multiple linear regression model was used to explore the impact of social capital on depressive symptoms. Moreover, the add-on PROCESS macro for SPSS was employed to measure the mediating effect of life satisfaction on the relationship between social capital and depressive symptoms.

Results: The regression results suggest that CES-D score was associated with trust (coefficient $=-0.1013, p<0.01)$. In addition, the protective role of trust was significantly stronger for older adults aged $70-79$, women, the poorest $1 / 3$, and the elderly who live in rural areas. Moreover, the mediation analysis results suggest that the effect of trust on depressive symptoms was fully mediated by life satisfaction.

Conclusion: This study reveals that social capital has a positive effect on depressive symptoms among the elderly, and the positive health effect shows significant age, gender, income, and location inequalities. Furthermore, this study also provides new evidence indicating that life satisfaction fully mediates the relationship between social capital and depressive symptoms. Improving social capital could be a promising way for China to promote healthy aging in the future.

Keywords: social capital, depressive symptoms, life satisfaction, elderly, China

\section{Introduction}

Due to the rapid increase of average life expectancy and sharp decrease of fertility rate, China has entered the population aging society since 2000, and China currently has the largest aging population in the world. In 2017, China had 240.90 million adults aged 60 and above, accounting for $17.30 \%$ of the total population, while the number of people aged 65 years and above reached 158.31 million, accounting for $11.4 \%$ of the total population. ${ }^{1}$ Older people usually have a higher prevalence of chronic diseases, which leads to an increase in public health-care expenditures. ${ }^{2}$ Moreover, it is reported that approximately 40,630 thousand Chinese older adults had physical activity limitations in $2015 .^{3}$ Furthermore, with the rapid process of urbanization, an increasing number of Chinese young adults migrate to cities for work and their parents who are left behind are known as 
"empty-nest" elderly. It is estimated that the number of "empty-nest" elderly in China was more than 100 million in 2014, and the rate of proportion of "empty-nest" families was over $40 \% .{ }^{4}$ The migration reduces the social support from their children and increases the probability of depression. ${ }^{5}$ Given the fact that older adults are associated with increasing health problems and thus utilize more health-care services, accelerated population aging brings about daunting challenges to the health-care system in China. To promote healthy aging, the Chinese government released Notice on the Division of Key Tasks in the 13th Five-year Planning for Healthy Aging in November 2017, which stated that it is necessary to provide mental health and care services for the elderly, promote the combination of medical care and nursing, and intensify the development of long-term care insurance and service systems.

Depression is one of the most common mental disorders among the elderly, which can lead to great suffering, decreased quality of life, and even suicide. ${ }^{6}$ In addition, the 2015 Global Burden of Disease Study suggested that depression is the fifteenth-leading cause of global disability-adjusted life years. ${ }^{7}$ Depression has become a serious health and social issue in recent years in China. In China, it is reported that approximately $30 \%$ of men and $43 \%$ of women aged 45 and above suffered from depressive symptoms in 2011. ${ }^{8}$ Moreover, a study based on nationwide survey indicated that about one-third of Chinese older adults who aged 75 and over suffered severe depressive symptoms in 2012. ${ }^{9}$ Furthermore, older adults with depressive symptoms are often overlooked and untreated because they have other health problems. ${ }^{10}$

The notion of "social capital", which was put forward by $\mathrm{P}$. Bourdieu, is a multi-dimensional and general concept. ${ }^{11}$ Social capital emphasizes social relationships between groups of people and can facilitate productive activity. $^{12,13}$ According to Putnam et al, social capital refers to the features of social organization, such as trust, networks, and norms that can improve the efficacy of society by facilitating coordinated actions. ${ }^{14}$ Generally speaking, social capital can be divided into cognitive social capital and structural social capital. ${ }^{14,15}$ The two types of social capital are quite different. The former refers to the norms, values, and reciprocity that lubricate such connections, such as trust and reciprocity, while the latter refers to the relationships, networks, and associations that connect people and groups, such as social participation. ${ }^{14}$

There is a growing academic research on the effect of social capital on health. Considering the fact that the theory of social capital was put forward and developed in western countries, existing studies mainly focused on the health effects of social capital in developed countries. ${ }^{16}$ Some studies suggested that social capital does have a positive effect on self-assessed health. ${ }^{17-20}$ Some researches have also investigated the impact of social capital on mental health measured by depressive symptoms. Liu et al found that social capital can alleviate depressive symptoms among the elderly in China. ${ }^{21}$ Wen et al also found that individual and community social capital significantly reduced depressive symptoms among rural elderly in China. ${ }^{22}$ Similarly, a study in South Africa suggested that depressive symptoms were associated with lower social capital among older adults. $^{23}$ However, social capital is also acknowledged to be a "double-edged" phenomenon, whose health effects are not always positive. ${ }^{24}$ There are two negative consequences of social capital: behavioral contagion and cross-level interactions between social cohesion and individual characteristics. $^{24}$ Some studies revealed that depressive symptoms were not significantly related to sub-dimensions of social capital, such as trust, ${ }^{25}$ reciprocity, ${ }^{26}$ and social participation. $^{27}$ A study even suggested that women who regularly engaged with people from different age groups outside of their families were more likely to report depression than those with less contact. ${ }^{28}$

Although a growing number of studies have found significant associations between social capital and depressive symptoms, few empirical studies have explored the underlying mechanisms through which social capital affects depressive symptoms. To fill this gap, this study aims to explore the relationship between social capital and depressive symptoms among the elderly in China, with a particular focus on the mediating role of life satisfaction. This study could shed light on future studies concerning the impact of social capital on geriatric depression.

\section{Methods \\ Data Source}

The data of this study were sourced from the 2016 wave of China Family Panel Studies (CFPS). CFPS data are freely available at http://www.isss.pku.edu.cn/cfps/. CFPS is a nationally representative longitudinal survey of households in China. It is designed and implemented by the Institute of Social Science Survey (ISSS) of Peking University, China. Moreover, its aim is to reveal the changes of society, economy, demography, education, health, and so forth in China, and provides high-quality micro-data for both public policy 
analysis and academic research. The first wave of CFPS was performed in 2008. CFPS data in 2016, as the seventh wave survey data, were released in August 2018. By using a multistage probability-proportional-to-size (PPS) sampling technique, approximately 57,000 individuals from 15,000 households in 25 provinces of China were sampled. This data is ideal for this study because it collects extensive information concerning social capital, depressive symptoms, life satisfaction, socio-demographic characteristics, healthrelated behavior, and so on. Given the fact that this study investigated the impact of social capital on depressive symptoms among older population, we removed the respondents under 60. After deleting cases with missing information, a total of 1243 older adults aged 60 and above were included in this study.

\section{Variables}

\section{Dependent Variable}

Description of variables is listed in Table 1. The Center of Epidemiological Survey-Depression Scale (CES-D Scale) was originally developed by Radloff and has been widely

Table I Description of Variables

\begin{tabular}{|c|c|}
\hline Variable & Description of Variables \\
\hline $\begin{array}{l}\text { CES-D score } \\
\text { Trust } \\
\text { Life satisfaction } \\
\text { Age }\end{array}$ & $\begin{array}{l}\text { Continuous variable } \\
\text { Continuous variable } \\
\text { Continuous variable } \\
\text { Continuous variable }\end{array}$ \\
\hline $\begin{array}{l}\text { Gender } \\
\text { Women }{ }^{\mathrm{a}} \\
\text { Men }\end{array}$ & Women $=0$, men $=1$ \\
\hline $\begin{array}{l}\text { Marital Status } \\
\text { Single, divorced or widowed }{ }^{\mathrm{a}} \\
\text { Married }\end{array}$ & $\begin{array}{l}\text { Single, divorced or } \text { widowed }=0, \\
\text { married }=1\end{array}$ \\
\hline $\begin{array}{l}\text { Years of education (year) } \\
\text { Household income per capita } \\
\text { (RMB) }\end{array}$ & $\begin{array}{l}\text { Continuous variable } \\
\text { Continuous variable }\end{array}$ \\
\hline $\begin{array}{l}\text { Residency Location } \\
\text { Living in rural area } \\
\text { Living in urban area }\end{array}$ & Living in urban area $=1$, else $=0$ \\
\hline $\begin{array}{l}\text { Smoking Status } \\
\mathrm{No}^{\mathrm{a}} \\
\text { Yes }\end{array}$ & $\begin{array}{l}\text { Never smoke } \\
\text { Smoke }=1 \text {, else }=0\end{array}$ \\
\hline $\begin{array}{l}\text { Frequency of physical exercise } \\
\text { (time) }\end{array}$ & Continuous variable \\
\hline
\end{tabular}

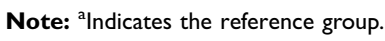

employed to measure mental health in the general population. $^{29}$ The CES-D Scale is an efficient screening instrument of depression with good validity, and previous studies have demonstrated its usefulness. ${ }^{30,31}$ In this study, the 20-item CES-D Scale was employed to measure depressive symptoms. In CFPS, older adults were asked to indicate the frequency of experiencing 10 feelings in the past week. The four responses are "rarely or none of the time ( $<1$ day)", "some or a little of the time (1-2 days)", "frequently (3-4 days)", and "most of the time (5-7 days)". Furthermore, out of the 20 questions in CES-D scale, 16 questions were used to measure the frequency of negative feelings and 4 questions were employed to measure the frequency of positive feelings. The positively oriented questions, such as how often the respondent enjoyed life and was hopeful for the future, were scored from 1 for most of the time to 4 for rarely or none of the time. In addition, the negatively oriented questions, such as how often the respondent felt depressed, felt that everything he or she did was an effort, were scored from 1 for rarely or none of the time to 4 for most of the time. Following Duncan and Rees, ${ }^{32}$ we summed these responses to the 20 questions to get a CES-D score, with a higher score indicating more severe depressive symptoms.

\section{Independent Variable}

Social capital is a multi-dimensional and general concept, and how to measure it remains controversial. Considering the fact that trust is an important type of cognitive social capital, this study used trust as a measure of social capital. In CFPS, older adults were requested to indicate their degree of trust of parents, neighbors, strangers, local government officials, and doctors, respectively. The responses to the five questions range from 0 to 10 , and a higher number suggests a higher degree of trust. We then summed the responses to obtain a trust score.

\section{Mediating Variable}

Previous studies suggested that a higher level of social capital, which indicates a higher level of trust, is associated with a higher level of life satisfaction. ${ }^{33-35}$ Furthermore, empirical evidence also showed that life satisfaction, as a kind of positive psychological status, can reduce depressive symptoms. $^{23,36-38}$ Based on this evidence, this study hypothesized that social capital may influence depressive symptoms by improving life satisfaction. To examine this hypothesis, life satisfaction was adopted as the mediating variable in the present study. In CFPS, respondents were requested to indicate their satisfaction with life. The 
responses range from 1 to 5 , with a higher number indicating higher degree of life satisfaction.

\section{Control Variables}

Previous studies indicated that socio-demographic characteristics and health-related behavior significantly impacted the health of older adults. ${ }^{39,40}$ In order to reduce the bias of omitted variables, two categories of control variables were used in this study. The first type of control variable describes the socio-demographic characteristics, including six variables: age, gender, marital status, years of education, household income per capita, residency location. Additionally, it is worth noting that we used the logtransformed household income per capita in the following regression models. The second type of control variable describes the health-related behavior, including two variables: smoking status and frequency of physical exercise, which, respectively, indicate whether or not the respondent smoked in the past month and the frequency he/she took physical exercise in the past week. Furthermore, this study also performed a Variance Inflation Factor (VIF) test. The test reveals that the VIF values of independent variable, mediating variable, and control variables are far lower than the critical value of 10 , which suggests that there was no serious multicollinearity across these regression models.

\section{Methodology}

In order to study the impact of social capital on depressive symptoms among older adults, this study built the following econometric model:

$$
C E S-D_{i}=\beta_{0}+\beta_{1} * S C_{i}+\beta_{2} * C V_{i}+\varepsilon_{i}
$$

where $i$ indicates the individual, $C E S-D_{i}$ denotes the CES-D score for the older adult $i, \beta_{0}$ refers to the intercept term, $\beta_{1}$ and $\beta_{2}$ are the regression coefficients for social capital and control variables, respectively. In addition, $S C_{i}$ indicates the social capital, $C V_{i}$ stands for the control variables, and $\varepsilon_{i}$ represents the error term.

Considering the fact that CES-D score used in this study is a continuous variable, a multiple linear regression model was used to explore the impact of social capital on depressive symptoms. The Add-on PROCESS macro for SPSS developed by A.F. Hayes, ${ }^{41}$ which is based on bootstrap method, has been widely used to account for mediation effects. $^{42-44}$ In this study, the Add-on PROCESS macro for SPSS was employed to measure the mediating effect of life satisfaction on the relationship between social capital and depressive symptoms.

\section{Ethical Considerations}

The study received ethical approval from the Ethics Committee of Shanghai Jiao Tong University.

\section{Results}

\section{Characteristics of the Study Population}

Table 2 reports the characteristics of the study population. The mean value of CES-D score, trust, and life satisfaction of respondents was $33.46,32.05$, and 3.87 , respectively. Furthermore, most respondents were aged 60-69, and more than half of them were women. Approximately

Table 2 Characteristics of the Study Population

\begin{tabular}{|c|c|}
\hline Variable & All $(N=1243)$ \\
\hline \multicolumn{2}{|l|}{ CES-D Score } \\
\hline Mean (SD) & $33.46(8.84)$ \\
\hline \multicolumn{2}{|l|}{ Trust } \\
\hline Mean (SD) & $32.05(7.94)$ \\
\hline \multicolumn{2}{|l|}{ Life Satisfaction } \\
\hline Mean (SD) & $3.87(1.07)$ \\
\hline \multicolumn{2}{|l|}{ Age } \\
\hline 60-69, n (\%) & $811(65.25)$ \\
\hline 70-79, n (\%) & $343(27.59)$ \\
\hline$\geq 80, \mathrm{n}(\%)$ & $89(7.16)$ \\
\hline \multicolumn{2}{|l|}{ Gender } \\
\hline Women, n (\%) & $634(51.01)$ \\
\hline Men, n (\%) & 609 (48.99) \\
\hline \multicolumn{2}{|l|}{ Marital Status } \\
\hline Single, divorced or widowed, n (\%) & $238(19.15)$ \\
\hline Married, n (\%) & $1005(80.85)$ \\
\hline \multicolumn{2}{|l|}{ Years of Education (year) } \\
\hline $0-9$, n (\%) & $1106(88.98)$ \\
\hline $10-15, \mathrm{n}(\%)$ & $130(10.46)$ \\
\hline$\geq 16, \mathrm{n}(\%)$ & $7(0.56)$ \\
\hline \multicolumn{2}{|l|}{ Household Income per Capita (RMB) } \\
\hline Mean (SD) & $17,316.39(119,635.60)$ \\
\hline \multicolumn{2}{|l|}{ Residency Location } \\
\hline Living in rural area, n (\%) & $659(53.02)$ \\
\hline Living in urban area, n (\%) & $584(46.98)$ \\
\hline \multicolumn{2}{|l|}{ Smoking Status } \\
\hline No, n (\%) & $94 I(75.70)$ \\
\hline Yes, n (\%) & $302(24.30)$ \\
\hline \multicolumn{2}{|l|}{ Frequency of Physical Exercise (Time) } \\
\hline $0-9, \mathrm{n}(\%)$ & $1226(98.63)$ \\
\hline $10-19, \mathrm{n}(\%)$ & $13(1.05)$ \\
\hline$\geq 20, \mathrm{n}(\%)$ & $4(0.32)$ \\
\hline
\end{tabular}


$80 \%$ of the respondents were married. Most respondents had less than 10 years of education. Moreover, the mean value of household income per capita was RMB 17,316.39 (US\$ 2431.47), and $53.02 \%$ of the respondents lived in rural areas. In addition, less than $25 \%$ of the respondents had smoked in the past month. Most respondents physically exercised fewer than 10 times in the past week.

\section{Overall Regression Results Analysis}

Table 3 shows the overall regression results. The overall regression results suggest that CES-D score was associated with trust (coefficient $=-0.1013, p<0.01$ ). This suggests trust can alleviate depressive symptoms among the elderly. Furthermore, it was found that being older, male, married, having more years of education and higher household

Table 3 Overall Regression Results

\begin{tabular}{|l|l|l|l|l|}
\hline Variable & Coefficient & S.E. & $\mathbf{t}$ & $\boldsymbol{P}>|\mathbf{t}|$ \\
\hline Age & -0.0703 & 0.0392 & -1.79 & 0.073 \\
Gender & -1.1357 & 0.5643 & -2.01 & 0.044 \\
Marital status & -2.5217 & 0.6487 & -3.89 & $<0.001$ \\
Years of education & -0.2991 & 0.0591 & -5.07 & $<0.001$ \\
Household income per & -0.9132 & 0.1696 & -5.38 & $<0.001$ \\
capita & & & & \\
Residency location & -0.7379 & 0.5138 & -1.44 & 0.151 \\
Smoking status & 0.5338 & 0.6285 & 0.85 & 0.396 \\
Frequency of physical & -0.0973 & 0.0696 & -1.40 & 0.162 \\
exercise & & & & \\
Trust & -0.1013 & 0.0350 & -2.89 & 0.004 \\
Constant & 53.8256 & 3.3736 & 15.96 & $<0.001$ \\
\hline Observations & 1243 & \\
\hline
\end{tabular}

income per capita were significantly associated with lower CES-D score. Moreover, the regression results also indicate that residency location, smoking status, and frequency of physical exercise had no significant impact on CES-D score.

\section{Regression Results in Different Subgroups}

In this section, we further examined whether the health benefit of social capital differs by age, gender, household income per capita, and residency location. Table 4 illustrates the regression results by age and gender. The regression results reveal that trust significantly relieved depressive symptoms for older adults aged 60-69 (coefficient $=-0.0773, p<0.10$ ) and 70-79 (coefficient $=$ $-0.1402, p>0.05$ ). Moreover, there was no evidence to suggest that the positive health effect was statistically significant for the older adults aged 80 and above (coefficient $=-0.0673, p>0.10$ ). Furthermore, the effect of trust on alleviating depressive symptoms was statistically significant for both women (coefficient $=-0.1080, p<0.05$ ) and men (coefficient $=-0.0916, p<0.10$ ), while the health effect was significantly stronger for women.

Table 5 displays the regression results by household income per capita and residency location. The regression results reveal that the effect of trust on CES-D score was at significant level for the poorest one-third of older adults (coefficient $=-0.2696, p<0.01$ ). However, the effect was not statistically significant for middle (coefficient $=-0.0035$, $p>0.10$ ) and richest older population (coefficient $=-0.0386$, $p<0.10$ ). In addition, the impact of trust on CES-D score was statistically significant in rural area (coefficient $=-0.1486$,

Table 4 Regression Results by Age and Gender

\begin{tabular}{|c|c|c|c|c|c|}
\hline \multirow[t]{2}{*}{ Variable } & \multicolumn{3}{|l|}{ By Age } & \multicolumn{2}{|l|}{ By Gender } \\
\hline & $60-69$ & 70-79 & $\geq 80$ & Women & Men \\
\hline Age & $-0.1736(0.1084)$ & $-0.1453(0.1705)$ & $-0.1701(0.3083)$ & $-0.1002 *(0.0563)$ & $-0.0244(0.0553)$ \\
\hline Gender & $-1.4420 * *(0.7134)$ & $-1.5562(1.0908)$ & $-0.1557(1.9433)$ & & \\
\hline Marital status & $-3.499 \mid * * *(0.8890)$ & $-2.506 \mid * *(I .|5| 2)$ & $1.2536(1.8166)$ & $-I .4806 *(0.87 \mathrm{II})$ & $-4.5423 * * *(0.9989)$ \\
\hline Years of education & $-0.3421 * * *(0.0726)$ & $-0.1450(0.1201)$ & $-0.494 \mid * *(0.1998)$ & $-0.3569 * * *(0.0897)$ & $-0.2227 * * *(0.0777)$ \\
\hline Household income per capita & $-1.3753 * * *(0.2275)$ & $-0.2604(0.3274)$ & $-0.3406(0.39 \mid 4)$ & $-1.1466 * * *(0.2526)$ & $-0.7129 * * *(0.2263)$ \\
\hline Residency location & $-0.1543(0.6364)$ & $-1.1479(1.0089)$ & $-2.4190(1.785 I)$ & $-0.8378(0.75 \mathrm{II})$ & $-0.3298(0.7028)$ \\
\hline Smoking status & $0.8324(0.7816)$ & $1.2020(1.2496)$ & $-2.0394(2.1056)$ & $2.7825 *(1.5553)$ & $0.0378(0.6742)$ \\
\hline Frequency of physical exercise & $-0.0574(0.0862)$ & $-0.1736(0.1369)$ & $-0.0772(0.2406)$ & $0.0249(0.1021)$ & $-0.2355^{* *}(0.0945)$ \\
\hline Trust & $-0.0773 *(0.0443)$ & $-0.1402 * *(0.0658)$ & $-0.0673(0.1139)$ & $-0.1080 * *(0.0476)$ & $-0.0916 *(0.0517)$ \\
\hline Constant & $64.3508(7.2628)$ & $55.3027(13.1904)$ & $54.8687(26.0615)$ & $57.1460(4.8777)$ & 49.2644 (4.7984) \\
\hline Observations & 811 & 343 & 89 & 634 & 609 \\
\hline
\end{tabular}

Notes: $* * * p<0.01,{ }^{* *} p<0.05,{ }^{*} p<0.10$. 
Table 5 Regression Results by Household Income per Capita and Residency Location

\begin{tabular}{|c|c|c|c|c|c|}
\hline \multirow[t]{2}{*}{ Variable } & \multicolumn{3}{|c|}{ By Household Income Per Capita } & \multicolumn{2}{|c|}{ By Residency Location } \\
\hline & Poorest I/3 & Middle $1 / 3$ & Richest I/3 & Rural Area & Urban Area \\
\hline Age & $-0.1218 *(0.0702)$ & $-0.0701(0.0723)$ & $-0.0026(0.0593)$ & $-0.0414(0.0555)$ & $-0.1125 * *(0.0552)$ \\
\hline Gender & $-1.7408^{*}(1.0321)$ & $-0.8570(1.0707)$ & $-1.1498(0.8227)$ & $-1.5892 *(0.8144)$ & $-0.7447(0.7879)$ \\
\hline Marital status & $-2.716 I^{* *}(1.1237)$ & $-3.4081 * * *(1.2297)$ & -1.0681 (0.9889) & $-2.388 \mathrm{I} * * *(0.9085)$ & $-2.7430 * * *(0.9322)$ \\
\hline Years of education & $-0.3049 * *(0.1225)$ & $-0.2530 * *(0.1130)$ & $-0.2150 * * *(0.0805)$ & $-0.2296 * *(0.0919)$ & $-0.3619 * * *(0.0762)$ \\
\hline Household income per capita & $-0.0573(0.2740)$ & $-4.6808 * * *(1.4936)$ & $-0.8233(0.7025)$ & $-1.2943 * * *(0.2430)$ & $-0.4735 * *(0.2357)$ \\
\hline Residency location & $-1.7519 *(1.0329)$ & $0.8238(0.8885)$ & $0.4035(0.8247)$ & & \\
\hline Smoking status & $1.7400(1.1196)$ & $-0.6066(1.1560)$ & $0.470 \mathrm{I}(0.9556)$ & $0.2544(0.8590)$ & $1.07 \mid 4(0.9236)$ \\
\hline Frequency of physical exercise & $0.0740(0.1327)$ & $0.0150(0.1298)$ & $-0.1821 *(0.1005)$ & $-0.1298(0.1033)$ & $-0.0708(0.0933)$ \\
\hline Trust & $-0.2696 * * *(0.0630)$ & $-0.0035(0.0613)$ & $-0.0386(0.0550)$ & $-0.1486 * * *(0.0473)$ & $-0.0272(0.0525)$ \\
\hline Constant & $56.9005(5.9193)$ & 84.6405 (14.6498) & $43.5504(8.1245)$ & $56.5867(4.8048)$ & $49.7946(4.7887)$ \\
\hline Observations & 415 & 414 & 414 & 659 & 584 \\
\hline
\end{tabular}

Notes: ${ }^{* * *} p<0.01,{ }^{* *} p<0.05,{ }^{*} p<0.10$.

$p<0.01)$. However, the effect was not statistically significant in urban areas (coefficient $=-0.0272, p>0.10$ ), which indicates that trust played a more important role in alleviating depressive symptoms among older adults who live in rural areas.

\section{Impact Mechanism Analysis}

In this section, we attempted to explore the mediating effect of life satisfaction on the relationship linking social capital and depressive symptoms among the aged, and Table 6 reports the results. According to the mediation analysis results, total effect of trust on depressive symptoms was at a significant level (effect $=-0.1013, \mathrm{SE}=0.0350,95 \% \mathrm{CI}$ : $[-0.1700,-0.0327])$. Furthermore, the direct effect of trust on life satisfaction was also at a significant level (coefficient $=0.0308, \mathrm{SE}=0.0043,95 \%$ CI: $[0.0224,0.0393])$. Moreover, when trust, life satisfaction, and the control variables were simultaneously input into the equation, the direct effect of trust on depressive symptoms was not statistically significant (effect $=-0.0342, \mathrm{SE}=0.0344,95 \%$ CI: $[-0.1018,0.0334])$. In addition, the indirect effect of trust through life satisfaction on depressive symptoms was statistically significant $(\mathrm{effect}=-0.0671, \mathrm{SE}=0.0124,95 \%$

Table 6 The Mediating Effect of Life Satisfaction

\begin{tabular}{|l|l|l|l|l|}
\hline & Effect & $\begin{array}{l}\text { Boot } \\
\text { SE }\end{array}$ & $\begin{array}{l}\text { Boot } \\
\text { LLCl }\end{array}$ & $\begin{array}{l}\text { Boot } \\
\text { ULCl }\end{array}$ \\
\hline Total effect & $-0.1013^{* * *}$ & 0.0350 & -0.1700 & -0.0327 \\
Direct effect & -0.0342 & 0.0344 & -0.1018 & 0.0334 \\
Indirect effect & $-0.067 I^{* * *}$ & 0.0124 & -0.0952 & -0.0459 \\
\hline
\end{tabular}

Note: $*_{* *}<<0.01$.
CI: $[-0.0952,-0.0459])$. Overall, the results suggest that the effect of trust on depressive symptoms was fully mediated by life satisfaction.

\section{Discussion}

In this study, we examined the effect of social capital on depressive symptoms among the elderly in China using the 2016 wave of CFPS data. Furthermore, this study also investigated the heterogeneous effects of social capital on depressive symptoms by age, gender, income, and location. In addition, the mediation analysis explored the possible underlying mechanism by which social capital affected the depressive symptoms through life satisfaction. The results suggest that social capital measured by trust had a positive effect on depressive symptoms among the elderly, which is consistent with the findings of Cao et $\mathrm{al}^{16}$ who also found that social capital measured by trust was significantly associated with geriatric depression.

The regression results by age indicate that older adults aged below 80 benefited more from social capital. This implies that the health effect of social capital was significantly stronger for the younger elderly, which is consistent with the findings of Liu et al. ${ }^{21}$ This may be due to the fact that older adults aged less than 80 have relatively stronger social interaction abilities. Furthermore, we also obtained evidence indicating that the positive health effect of social capital was significantly stronger for women. The reason may lie in the fact that women bear the main responsibilities for bringing up children and have more social interactions and social capital than men. This finding is consistent with the finding reported in China ${ }^{45}$ while it is in contrast to results reported in other countries, ${ }^{46,47}$ 
which suggested that women tend to derive fewer health benefits from social capital than men do. It was also found that the health effect of social capital was significantly stronger for the poorest one-third of older adults. This can be explained by the fact that the poor elderly need more help from friends, neighbors, and relatives due to the restriction of funds, while the wealthy older people need less. In addition, this study also found that rural older people benefited more from social capital than urban older people do, which is not consistent with the finding of Liu et $\mathrm{al}^{21}$ who discovered that the effect of social capital on mental health is not heterogeneous across area of residence. These inconsistencies may be due to various reasons, such as using different measurements of social capital.

Moreover, our mediation analysis results suggest that life satisfaction fully mediated the relationship between social capital and depressive symptoms. A study which is conducted by Baron and Kenny indicated that full mediation effect is the strongest demonstration of mediation. ${ }^{48}$ That is to say, social capital indirectly affected depressive symptoms by increasing life satisfaction among the older people.

This study has several policy implications. Firstly, it is quite necessary for the government to provide more subsidies to organize some community events, thereby facilitating interaction and promoting trust among the elderly. Secondly, there is also an urgent need to encourage trust in residents in their relationships with each other. ${ }^{49}$ Thirdly, the government should pay more attention to the health effect disparities of social capital by age, gender, income, and location.

This study has several strengths. To the best of our knowledge, this is the first study to explore the mediating effect of life satisfaction on the relationship between social capital and depressive symptoms among the elderly in the Chinese context. In addition, this study employed nationally representative survey data to study the impact of social capital on depressive symptoms among the elderly, which indicates that the conclusion of this study can be generalized to the whole country. Based on social capital theory, this study explored the impact mechanism of social capital on depressive symptoms and found the mediating effect of life satisfaction, which is a supplement to the existing research on the health effect of social capital.

There are several limitations to this study which should be noted. Firstly, only correlation rather than causal relationship was explored due to the cross-sectional design of this study.
More longitudinal researches on the relationship between social capital and depressive symptoms are needed. Secondly, this study only focused on the effect of cognitive social capital on depressive symptoms, while it ignored the health effect of structural social capital. Future studies should explore the relationship between different forms of social capital and depressive symptoms. Thirdly, given the fact that the information we obtained from CFPS was self-reported, recall bias may exist in this study, which may significantly affect the results. In addition, the measure of trust might be biased by psychological adjustment and overall well-being, which may also affect the accuracy of the results. Fourthly, some factors, such as urbanization and tea consumption, ${ }^{40,50}$ have been examined that have significant impacts on depressive symptoms among the elderly. However, we cannot control these factors due to the unavailability of data.

\section{Conclusions}

In summary, this study reveals that social capital has a positive effect on depressive symptoms among the elderly, and the positive health effect shows significant age, gender, income, and location inequalities. Furthermore, this study also provides new evidence indicating that life satisfaction fully mediates the relationship between social capital and depressive symptoms. Improving social capital could be a promising way for China to promote healthy aging in the future.

\section{Abbreviations}

CFPS, China Family Panel Studies; CES-D Scale, Center of Epidemiological Survey-Depression Scale; VIF, Variance Inflation Factor.

\section{Acknowledgments}

This study was funded by National Social Science Foundation of China (15BJL003), Shanghai Philosophy and Social Science Planning Project (2014BJL002), Research Foundation of Shanghai Municipal Development and Reform Commission of 2018, Scientific Research Foundation of Outstanding Young Teachers of Shanghai Jiao Tong University and SMC of 2016, and Urban Governance Foundation in Humanities and Social Sciences in Shanghai Jiao Tong University (16JCCS16).

\section{Disclosure}

The authors report no conflicts on interest in this work. 


\section{References}

1. National Bureau of Statistics, People's Republic of China. China Statistical Yearbook 2018. Beijing: China Statistics Press; 2018.

2. Sirven N, Debrand T. Social participation and healthy ageing: an international comparison using SHARE data. Soc Sci Med. 2008;67 (12):2017-2026. doi:10.1016/j.socscimed.2008.09.056

3. National Health Commission of the People' Republic of China. The 13th five-year planning for healthy aging; 2017. Available from: http://www.nhc.gov.cn/rkjcyjtfzs/zcwj2/201703/ 53164cb31b494359a21c607713451342.shtml. Accessed Oct 9, 2019.

4. Jiang C.The analysis on status of the aging population in China and the strategy and measures should be taken during the "13th FiveYear" period. Globalization. 2016;6(8):90-105.

5. Zhong Y, Schön P, Burström B, et al. Association between social capital and health-related quality of life among left behind and not left behind older people in rural China. BMC Geriatr. 2017;17 (1):287. doi:10.1186/s12877-017-0679-x

6. Xu Y, Yang J, Gao J, et al. Decomposing socioeconomic inequalities in depressive symptoms among the elderly in China. BMC Public Health. 2016;16(1):1214. doi:10.1186/s12889-016-3876-1

7. Kassebaum NJ, Arora M, Barber RM, et al. Global, regional, and national disability-adjusted life-years (DALYs) for 315 diseases and injuries and healthy life expectancy (HALE), 1990-2015: a systematic analysis for the Global Burden of Disease Study 2015. Lancet. 2016;388(10053):1603-1658. doi:10.1016/S0140-6736(16) 31460-X

8. Lei X, Sun X, Strauss J, et al. Depressive symptoms and SES among the mid-aged and elderly in China: evidence from the China Health and Retirement Longitudinal Study national baseline. Soc Sci Med. 2014;120:224-232. doi:10.1016/j.socscimed.2014.09.028

9. Qin X, Wang S, Hsieh CR. The prevalence of depression and depressive symptoms among adults in China: estimation based on a National Household Survey. China Econ Rev. 2018;51:271-282. doi:10.1016/j.chieco.2016.04.001

10. World Health Organization. Mental Health of Older Adults; 2017. Available from: http://www.who.int/news-room/fact-sheets/detail/ mental-health-of-older-adults. Accessed Jun 9, 2019.

11. Webber M, Huxley P, Harris T. Social capital and the course of depression: six-month prospective cohort study. J Affect Disord. 2011;129(1-3):149-157. doi:10.1016/j.jad.2010.08.005

12. Onyx J, Bullen P. Measuring social capital in five communities. J Appl Behav Sci. 2000;36(1):23-42. doi:10.1177/0021886300361 002

13. Coleman JS. Social capital in the creation of human capital. Am J Sociology. 1988;94:S95-S120. doi:10.1086/228943

14. Putnam RD, Leonardi R, Nanetti RY. Making Democracy Work: Civic Traditions in Modern Italy. Princeton: Princeton University Press; 1994.

15. Kawachi I. Commentary: social capital and health: making the connections one step at a time. Int J Epidemiol. 2006;35(4):989-993. doi:10.1093/ije/dyl117

16. Cao W, Li L, Zhou X, et al. Social capital and depression: evidence from urban elderly in China. Aging Ment Health. 2015;19 (5):418-429. doi:10.1080/13607863.2014.948805

17. Meng T, Chen H. A multilevel analysis of social capital and self-rated health: evidence from China. Health Place. 2014;27:38-44. doi:10. 1016/j.healthplace.2014.01.009

18. Zhang J, Xu S, Lu N. Community-based cognitive social capital and self-rated health among older chinese adults: the moderating effects of education. Int J Environ Res Public Health. 2019;16(15):2741. doi:10.3390/ijerph16152741

19. Yip W, Subramanian SV, Mitchell AD, et al. Does social capital enhance health and well-being? Evidence from rural China. Soc Sci Med. 2007;64(1):35-49. doi:10.1016/j.socscimed.2006.08.027
20. Zhou G, Fan G, Shen G. The income disparity, the social capital and health: a case study based on china family panel studies. Manage World. 2014;30(7):12-21.

21. Liu GG, Xue X, Yu C, et al. How does social capital matter to the health status of older adults? Evidence from the China Health and Retirement Longitudinal Survey. Econ Hum Biol. 2016;22:177-189. doi:10.1016/j.ehb.2016.04.003

22. Wen X, Wen F, Ye L. The effects of social capital on mental health of the Chinese rural elderly: an analysis based on survey data from the China health and retirement longitudinal study. China Rural Surv. 2017;38(4):130-144.

23. Ramlagan S, Peltzer K, Phaswana-Mafuya N. Social capital and health among older adults in South Africa. BMC Geriatr. 2013;13 (1):100. doi:10.1186/1471-2318-13-100

24. Villalonga-Olives E, Kawachi I. The dark side of social capital: a systematic review of the negative health effects of social capital. Soc Sci Med. 2017;194:105-127. doi:10.1016/j.socscimed.2017.10.020

25. Pollack CE, Von Dem Knesebeck O. Social capital and health among the aged: comparisons between the United States and Germany. Health Place. 2004;10(4):383-391. doi:10.1016/j.healthplace.2004. 08.008

26. Norstrand JA, Xu Q. Social capital and health outcomes among older adults in China: the urban-rural dimension. Gerontologist. 2011;52 (3):325-334. doi:10.1093/geront/gnr072

27. Bassett E, Moore S. Social capital and depressive symptoms: the association of psychosocial and network dimensions of social capital with depressive symptoms in Montreal, Canada. Soc Sci Med. 2013;86:96-102. doi:10.1016/j.socscimed.2013.03.005

28. Ferlander S, Stickley A, Kislitsyna O, et al. Social capital-a mixed blessing for women? A cross-sectional study of different forms of social relations and self-rated depression in Moscow. BMC Psychol. 2016;4(1):37. doi:10.1186/s40359-016-0144-1

29. Radloff L. The CES-D scale: a self-report depression scale for research in the general population. Appl Psychol Meas. 1977;1 (3):386-401. doi:10.1177/014662167700100306

30. Tachibana T, Goto R, Sakurai T, et al. Do remittances alleviate negative impacts of disaster on mental health? A case of the 2015 Nepal earthquake. Soc Sci Med. 2019;238:112460. doi:10.1016/j. socscimed.2019.112460

31. Luo MS, Chui EWT, Li LW. The Longitudinal Associations between physical health and mental health among older adults. Aging Ment Health. 2019;1-9. doi:10.1080/13607863.2019.1655706

32. Duncan B, Rees DI. Effect of smoking on depressive symptomatology: a reexamination of data from the National Longitudinal Study of Adolescent Health. Am J Epidemiol. 2005;162(5):461. doi:10.1093/ aje/kwi219

33. Elgar FJ, Davis CG, Wohl MJ, et al. Social capital, health and life satisfaction in 50 countries. Health Place. 2011;17(5):1044-1053. doi:10.1016/j.healthplace.2011.06.010

34. Bjørnskov C. The multiple facets of social capital. Eur J Polit Econ. 2006;22(1):22-40. doi:10.1016/j.ejpoleco.2005.05.006

35 . Bjørnskov C. The happy few: cross-country evidence on social capital and life satisfaction. Kyklos. 2003;56(1):3-16. doi:10.1111/kykl. 2003.56.issue-1

36. Daig I, Herschbach P, Lehmann A, et al. Gender and age differences in domain-specific life satisfaction and the impact of depressive and anxiety symptoms: a general population survey from Germany. Qual Life Res. 2009;18(6):669-678. doi:10.1007/s11136-009-9481-3

37. Swami V, Chamorro-Premuzic T, Sinniah D, et al. General health mediates the relationship between loneliness, life satisfaction and depression. Soc Psychiatry Psychiatr Epidemiol. 2007;42(2):161-16 6. doi:10.1007/s00127-006-0140-5

38. Koivumaa-Honkanen H, Kaprio J, Honkanen R, et al. Life satisfaction and depression in a 15-year follow-up of healthy adults. Soc Psychiatry Psychiatr Epidemiol. 2004;39(12):994-999. doi:10.1007/ s00127-004-0833-6 
39. Glanville JL, Story WT. Social capital and self-rated health: clarifying the role of trust. Soc Sci Res. 2018;71:98-108. doi:10.1016/j. ssresearch.2018.01.002

40. Shen K, Zhang B, Feng Q. Association between tea consumption and depressive symptom among Chinese older adults. BMC Geriatr. 2019;19(1):1-8. doi:10.1186/s12877-019-1259-z

41. Hayes AF. The PROCESS macro for SPSS and SAS; 2013. Available from: http://www.processmacro.org/.

42. Sak G, Rothenfluh F, Schulz PJ. Assessing the predictive power of psychological empowerment and health literacy for older patients' participation in health care: across-sectional population-based study. BMC Geriatr. 2017;17(1):59. doi:10.1186/s12877-017-0448-x

43. Ghimire S, Baral BK, Pokhrel BR, et al. Depression, malnutrition, and health-related quality of life among Nepali older patients. $B M C$ Geriatr. 2018;18(1):191. doi:10.1186/s12877-018-0881-5

44. Sun LY, Pan W, Chow IHS. The role of supervisor political skill in mentoring: dual motivational perspectives. J Organ Behav. 2014;35 (2):213-233. doi:10.1002/job.1865

45. Xue X, Liu G. Does social capital determine health status: evidence from China health and retirement longitudinal survey. Finance Trade Econ. 2012;33(8):113-121.
46. Berry HL, Welsh JA. Social capital and health in Australia: an overview from the household, income and labour dynamics in Australia survey. Soc Sci Med. 2010;70(4):588-596. doi:10.1016/j.socscimed. 2009.10.012

47. Ferlander S, Mäkinen IH. Social capital, gender and self-rated health: evidence from the Moscow health survey 2004. Soc Sci Med. 2009;69 (9):1323-1332. doi:10.1016/j.socscimed.2009.08.009

48. Baron RM, Kenny DA. The moderator-mediator variable distinction in social psychological research: conceptual, strategic, and statistical considerations. J Pers Soc Psychol. 1986;51(6):1173. doi:10.1037/ 0022-3514.51.6.1173

49. Forrest R, Kearns A. Social cohesion, social capital and the neighbourhood. Urban Stud. 2001;38(12):2125-2143. doi:10.1080/ 00420980120087081

50. Wang R, Xue D, Liu Y, et al. The relationship between urbanization and depression in China: the mediating role of neighborhood social capital. Int J Equity Health. 2018;17(1):105. doi:10.1186/s12939018-0825-x
Risk Management and Healthcare Policy

\section{Publish your work in this journal}

Risk Management and Healthcare Policy is an international, peerreviewed, open access journal focusing on all aspects of public health, policy, and preventative measures to promote good health and improve morbidity and mortality in the population. The journal welcomes submitted papers covering original research, basic science, clinical \& epidemiological studies, reviews and evaluations,

\section{Dovepress}

guidelines, expert opinion and commentary, case reports and extended reports. The manuscript management system is completely online and includes a very quick and fair peer-review system, which is all easy to use. Visit http://www.dovepress.com/testimonials.php to read real quotes from published authors. 